\title{
La función nomofiláctica como mecanismo de unificación en la interpretación del derecho
}

The nomophilactic function as a mechanism of unification in the interpretation of law

Alizia Agnelli Fagioli ${ }^{1} \underline{\mathrm{ORCID}}$

Marily Rafaela Fuentes Águila ${ }^{2} \underline{\mathrm{ORCID}}$

Pedro Enrique Castellanos Fuentes ${ }^{3 凶 0 \text { RCID }}$

Fecha correspondencia:

Recibido: 3 de septiembre de 2019.

Revisión: 30 de septiembre de 2019.

Aceptado: 17 de octubre de 2019.

\section{Forma de citar:}

Fagioli, Alizia; Fuentes, Marily

Rafaela; Castellanos, Pedro Enrique.

La función nomofiláctica como

mecanismo de unificación en la

interpretación del derecho. Revista

CES Derecho. Vol. 10, No. 2, julio -

diciembre de 2019, 591-604.

Open access

Términos de uso

Licencia creative commons

Ética de publicaciones

Revisión por pares

Gestión por Open Journal System

DOl: http://dx.doi.org/10.21615/

cesder.10.2.3

ISSN: 2145-7719

Sobre los autores:

1. Abogado y profesora, doctora

en ciencias de la educación,

postdoctora en estudios

postdoctorales. Docente titular e

investigadora de la Universidad

Metropolitana de Ecuador.

2. Abogado. Doctora en Ciencias

Jurídicas. Docente Titular e

Investigadora de la Universidad

Metropolitana de Ecuador.

\section{Resumen}

El presente artículo tiene como propósito reflexionar acerca de la vigencia de la función nomofiláctica de la casación ante las fuertes críticas de que ha sido objeto en la etapa contemporánea, en la que, se ha dicho, la nomofilaxis ha quedado atrás con motivo de otros fines que tiene el recurso. El trabajo llama la atención acerca de las causas por las cuales no puede perderse de vista que, con independencia de las razones para aplicar la justicia en el caso concreto, los jueces no pueden alejarse, en la actividad de interpretación, de la ley para cumplir otros fines, pues el orden normativo representa la expresión de la voluntad del interés general de los ciudadanos, de modo que estos en el ejercicio de sus funciones deberán interpretar y aplicar la ley, sin incurrir en abusos, ni arbitrariedades sustentados en teorías que distorsionan uno de los fines más antiguos de la casación: la nomofilaxis.

Palabras clave: Función nomofiláctica, unificación, interpretación, casación.

\section{Abstract}

The purpose of this article is to reflect on the validity of the nomofilactic function of the cassation in the face of the strong criticisms that it has been subject to in the contemporary stage, in which, it has been said, the nomofilaxis has been left behind for other purposes that has the resource. The work draws attention to the causes for which it cannot be overlooked that, regardless of the reasons for applying justice in the specific case, judges cannot move away, in the activity of interpretation, from the law to comply other purposes, since the normative order represents the expression of the will of the general interest of citizens, so that these in the exercise of their functions must interpret and apply the law, without incurring abuse, or arbitrariness based on theories that distort one of the oldest purposes of the cassation: the nomofilaxis.

Keywords: Nomofillactic function, unification, interpretation, matching.

\section{Introducción}

A pesar de la trascendencia jurídica que ha tenido la nomofilaquia en la interpretación y aplicación del Derecho, en la etapa contemporánea algunos autores han puesto en duda su utilidad, sobre todo cuando se trata de 
3. Abogado. Ms.C. en Ciencias Jurídicas. justificar a través del recurso de casación la necesidad de aplicar la justicia al caso concreto. La defensa de la letra de la norma, entendida como nomofilaquia, ha pasado a un nivel secundario en las corrientes actuales.

La casación está siendo objeto de fuertes embestidas por su formalidad y esquematismo. La doctrina más progresista insiste en que existen nuevos paradigmas para aplicar el recurso de casación pues ya no es lo que era antes, según señala (Guasp, 1950, pág. 109) en la siguiente afirmación:

El recurso no cumple una función exclusivamente nomofiláctica o uniformadora, sino que, básicamente, desempeña una función procesal, de respuesta o satisfacción jurídica de las pretensiones de las partes, en la que no sólo está en juego la defensa de la legalidad, sino que, como en todo proceso, se trata de hacer justicia en el caso concreto. Y, de modo coherente con esta concepción, la casación debe dar lugar a la posibilidad de denunciar el error de hecho en la apreciación de las pruebas, con el que, aunque de forma restringida, posibilita la revisión de los hechos declarados probados por el Tribunal a quo.

Por otra parte, Pastor en su texto sobre "Evolución histórica y futuro de la casación penal" concluía textualmente:

Los motivos que justificaron la configuración de la casación como un medio destinado a asegurar la vigencia de la ley (función nomofiláctica) y la unidad de la jurisprudencia (función uniformadora) no son defendibles entre nosotros porque nuestro orden jurídico-político no permite la realización efectiva de esas funciones. Tampoco la soberanía del jurado puede justificar la limitación del recurso, pues aun los cuerpos judiciales de participación ciudadana ven restringidos sus poderes ante la obligación de fundamentar su decisión y, de ese modo, permitir la eficacia del derecho del condenado a controlar ese veredicto con un recurso que el Estado debe indeclinablemente prescribir. (Pastor, 2014, pág.19)

Si bien los mencionados paradigmas de justicia que defienden estos autores resultan apropiados, pues los valores asentados en la justicia y el derecho de los hombres a obtener un fallo justo ocupan un lugar primordial, también es cierto que bajo este pretexto pueden cometerse un cúmulo de arbitrariedades que imponen la necesidad de rescatar la importancia de la ley y la unidad del Derecho en las decisiones jurisdiccionales. Dejar abierta la posibilidad de que los jueces puedan incorporar en sus análisis todas aquellas consideraciones sobre doctrinas, principios y normas que estimen aplicables, sin sujeción a la legalidad y a una política única de interpretación, distorsiona la ley y crea un caos que impacta negativamente en la sociedad, al desconocer lo que es correcto y lo que no lo es.

No son pocas las sentencias dictadas que no permiten el control jurisdiccional, ya sea porque son enrevesadas en su lenguaje, o porque utilizan tantas doctrinas que pudieran aparentar que la intención de su redactor era precisamente provocar el no entendimiento y otras han sido argumentadas de tal forma que, aún en contra de la ley, pareciera que sus motivaciones son legales, cuando no lo son. De ahí que este trabajo tiene como objetivo enaltecer el respeto a la ley en la casación junto a otras finalidades en las que se incluye trazar líneas de interpretación uniformes. 
El método histórico jurídico, unido al análisis, síntesis y el razonamiento lógico han posibilitado la reflexión sobre este tema, de vital importancia para que los operadores del Derecho y fundamentalmente los jueces no se alejen de la mesura y equilibrio que ha de lograrse en la interpretación de las teorías, doctrinas y conceptos que hoy reclaman una mejor justicia, pero siempre ajustada a la norma vigente. La ley representa la voluntad soberana de los pueblos concentrada normativamente, pues los órganos legislativos de los Estados aprueban las leyes en virtud de la delegación que sus ciudadanos le han concedido.

La problemática que se produce cuando los jueces abusan del poder otorgado, interpretando a su capricho y conveniencia los preceptos legales, reafirma que este proceder está muy lejos de los principios de legalidad y seguridad jurídica que reclama el Constitucionalismo contemporáneo. Cuando la ley establece que se aplique la justicia por encima de las formalidades no autoriza al juez a dictar sentencias bajo criterio e interés personal, por lo que se requiere hacer contrapeso, mediante la reflexión, a los excesos en la interpretación judicial, para lo que es preciso rescatar el imperio de la ley y su importancia expresada en la función nomofiláctica.

\section{Desarrollo}

La interpretación uniforme de la ley se fundamenta en la conformación de una unidad jurídica y en garantizar el principio de igualdad ante ella, esto exige el correcto estudio, exégesis y aplicación de la norma jurídica dentro de una nación, obteniendo así, una interpretación unificada para que pueda ser obligatoria para todos los tribunales. Con ello se persigue tener una visión coherente, social y racional de las decisiones que emanan de los Tribunales o Cortes Supremas de Justicia que se encargan de revisar y decidir los recursos de casación, cuyo norte es el derecho al debido proceso, el respeto a las normas y principios generales de Derecho y el derecho a la defensa, sin vulnerar la estructura jurídica que le atañe para así poder cumplir sus funciones ante una sociedad que reclama y merece una buena, expedita, justa y correcta administración de justicia.

El Estado constituye toda organización humana donde se encuentra la totalidad de la población de un país, ordenada de forma social, política y económica, a través del conjunto de organizaciones que rigen la vida en sociedad. Por lo tanto, el Estado a través de sus instituciones, órganos y atribuciones de carácter público viene a constituir el gobierno de una nación, donde se debe resguardar y salvaguardar que las normas jurídicas se respeten y se cumplan y donde el poder judicial a través de los órganos que lo conforman vele que la ley se aplique, a través del juez, a quien le corresponde garantizar la aplicación de los principios que rigen el proceso judicial.

En virtud de que el juez como director del proceso, aplica la ley, es necesario que el Estado para ello, cuente con mecanismos para asegurar que los administradores de justicia cumplan con su función, lo que quiere decir que deben aplicar de manera imparcial y correcta las normas legales. Es necesario mantener una seguridad jurídica a los ciudadanos y una de las formas es respetando la imperatividad del ordenamiento jurídico.

Para que se respete en un país, la estructura del poder judicial es indispensable que los ciudadanos cuenten con una tutela judicial efectiva; que no exista injerencia política, ni de carácter económico, que el poder judicial cuente con una autonomía desde el ámbito administrativo, que posea un personal capacitado en el ejercicio de sus funciones. Todo esto se traduce en procesos transparentes, en el cumplimiento 
de los plazos procesales y en mejores decisiones ajustadas a derecho en busca de la defensa del orden jurídico.

Pérez señala, "Se debe allanar el camino, ante errores groseros, absurdos, evidentes, irregularidades de procedimiento, violación a los principios de contradicción, derecho de defensa y el debido proceso, como también a las garantías constitucionales". (Pérez, 2011, p.73).

Los errores, vacíos y omisiones que se pueden presentar en los dictámenes judiciales traen como consecuencia el incurrir en vulneraciones a la técnica jurídica y a las especificidades propias del estado de derecho. Según Gómez: "Se debe considerar que la ley puede ser vulnerada y transgredida por los dictámenes judiciales dictados por los órganos judiciales de instancia en virtud de una infracción a la ley o su relajamiento, lo cual se presenta ante la inobservancia del sistema judicial". (Gómez, 2011, p. 56)

Las constantes omisiones de la norma que apuntala el deber ser, en los dictámenes judiciales, genera que se puedan materializar excesos, cuando dentro de lo decidido resulten aspectos contradictorios e inexactos que evidencien que el fallo puede vulnerar los principios fundamentales del orden normativo inherentes tanto en el orden sustantivo como el adjetivo, lo cual colocaría en una situación de indefensión a los justiciables y comprometería la credibilidad efectiva del propio sistema de administración de justicia.

Bajo este contexto, la función nomofiláctica debe contribuir a establecer de manera significativa el espíritu, propósito y razón de la norma, de manera que no se pueda menoscabar su sentido e interpretación, lo que permite fortalecer la seguridad jurídica. Por lo tanto, se justifica que con la función nomofiláctica existe la llamada bilateralidad, que se traduce en que existe un ente revisor de las sentencias para evitar que de manera rebelde o contumaz se pueda reincidir en sentencias violatorias del ordenamiento jurídico, siendo necesario para ello el recurso de casación.

En esencia, la función nomofiláctica presentada por vía de recurso de casación debe propender a la protección de la ley de manera específica, sin que ello impida la presentación de otras medidas que, en efecto, pudiesen darse para resguardar a los particulares de sus derechos. La naturaleza de esta atribución pasa por declarar el orden jurídico público como situación inviolable por el propio sistema de administración de justicia.

Todo ello se traduce en el nexo que debe existir entre el recurso de casación, la función nomofiláctica y la interpretación de las normas jurídicas acorde a las formas que la propia ley establece, de manera que la actividad jurisdiccional conduzca a la uniformidad en las decisiones jurisdiccionales. La actuación conforme a estas reglas se corresponde con el fin superior de protección del derecho objetivo, universal y abstracto. La nomofilaxis, ejercida por los jueces representantes de los órganos de poder del Estado, encargados de impartir justicia, puede conducir a la uniformidad y seguridad jurídica que demandan los ciudadanos siempre que en el ejercicio de sus funciones interpretativas se ajusten a la ley.

\section{Fundamentos teóricos de la función nomofiláctica}

Desde sus orígenes, la función nomofiláctica constituía un mecanismo que le permitía a los entes judiciales garantizar que, de manera inequívoca y específica, se aplicara la norma. Es evidente que en el desarrollo de esta función se supeditaba el ente 
competente a revisar los distintos grados, estados y fases del proceso judicial para fijar la eficacia de la norma jurídica.

Los comienzos de la función nomofiláctica del sistema judicial, se encuentran en el derecho romano, en virtud que se establecía la protección del derecho tal como ha sido previsto por el legislador. A su vez, dentro del derecho italiano, De la Rúa (2000, p.145) expresa:

Es en el disperso derecho estatutario italiano, posterior a la caída del imperio romano, que nace un recurso especial para anular una sentencia afectada por un vicio de derecho. La nulidad deja de ser equiparada a la inexistencia y se convierte en un vicio de una sentencia existente. Precisamente, la acción se dirige a obtener la declaración de nulidad de una sentencia que ya no se consideraba inexistente sino inválida. Aparece la distinción entre querela iniquitatis y querela nullitatis. Esta última constituía una acción que tenía por fin llevar ante un juez superior una sentencia viciada por error iuris in iudicando, por lo que refleja la estructura actual de la casación.

Dentro del ámbito normativo italiano, se establecían formas para atacar y desafectar los dictámenes judiciales que pudiesen suponer el menoscabo de la norma fundamental. Era evidente que dentro de ese orden de derecho se propendía a prescindir de la validez de una sentencia por considerar que había sido dictada desconociendo el orden jurídico, legítimo o valedero, de esta forma se entendía que la función se justificaba dentro de un paradigma de sanción, de acuerdo con el cual se debía desmeritar cualquier decisión o acto que en esencia era arbitrario y antijurídico, lesivo del orden público reconocido.

Por su parte, la doctrina española con la influencia italiana concibe que "la nomofiláxis es como racionalización del derecho para depurar la jurisprudencia, permitiendo que dentro de la uniformidad se eviten los estancamientos": (Porras, 2005, p.67), todo ello dota al sistema, de los derechos y garantías para certificar y garantizar la seguridad jurídica, la tutela judicial efectiva y la igualdad ante la ley.

En el derecho francés la función nomofiláctica tiene según opinión de Vescovi, "un nexo con la casación y cumplía una función política al preservar la autoridad del legislador y la jerarquía del emperador, impidiendo la rebelión del juez": (Vescovi, 1998, p.230) expresaba que de esta forma entre la voluntad del legislador y del juzgador en la producción de la norma, era superior la postura del legislador.

Cuando en Francia la función jurisdiccional comenzó a revelarse contra la legislación real se creó un órgano centralizado y supremo para conservar la unidad del poder real que fue denominado Conseil des parties que sería el germen del tribunal de casación y que concretamente fue creado para fiscalizar las decisiones de los jueces y el cumplimiento de la ley. Desde este momento puede observarse la creación de un órgano de control ubicado al lado del poder legislativo con una función nomofiláctica, es decir, dirigida a la preservación de la ley y a controlar el poder de los jueces inferiores para neutralizar cualquier decisión que contrariara la soberanía legislativa. (Chiovenda, págs 490-492)

En Francia, la corte de casación no era un organismo del poder judicial, sino que trabajaba junto a la asamblea legislativa, cuyo fin era evitar y controlar las decisiones que emanaban de los tribunales, así como utilizar pretextos de la hermenéutica de 
las leyes que interrumpieran funciones que le atañen solamente al poder legislativo. La finalidad tradicional de la casación, consistía en la defensa de la letra de la norma (nomofiláctica) y la unificación de la interpretación de la ley.

"El tribunal de casación, surgió como todos los institutos revolucionarios, de las abstracciones ideológicas de Rousseau, pero de una influencia más directa de las doctrinas de Montesquieu, en especial del principio de la separación de poderes sustituyendo el principio de la bipartición por el de tripartición de poderes." (Fenech, 1992, p.274).

En virtud de lo expuesto, la casación es donde se ejerce la función de carácter nomofiláctico producto del fraccionamiento de poderes, en virtud de que se atribuye a un poder la competencia de controlar al otro evitando que se incurra en abusos y desviaciones de derecho donde se puedan afectar los propios derechos de los órganos del Estado y de los justiciables. La función nomofiláctica surge para Hitters, "de la concepción de este instituto luego de la Revolución Francesa para satisfacer el prurito de tener y mantener a la ley como expresión de la voluntad soberana, y que al ser interpretada por los jueces no podía ser desvirtuada en sus fines supremos". (Hitters, 1995, p.99).

Los jueces deben velar por el fin supremo de un sistema legal, al impedir de manera manifiesta que se contravenga el orden público, esto permite mantener la integralidad del sistema legal y evitar la inseguridad jurídica o trasgresión del fin teleológico en los supuestos que se considere. Cuando a mediados del año 1837, se instaura la eficacia de la interpretación de las decisiones de la corte suprema de justicia, y con ello se alcanza la función de nomofilaxia, se convierte la corte suprema en ordenadora de la interpretación jurisprudencial, cuyo fin es de carácter político y no establecido en ningún dispositivo legal.

Esto correspondió al fundamento de la casación, la cual controla las decisiones de los jueces, "con una acentuada función política dentro del ámbito extraprocesal, para asegurar la vigencia uniforme del derecho objetivo a través de la unificación de la jurisprudencia que se traduce en la función nomofiláctica de la casación". (Cafferata, 2003, p.592).

De esta manera existe una relación directa entre la función nomofiláctica y la casación, cuyo fin no es otro de garantizar el cumplimiento y acatamiento de la norma de derecho objetivo, con lo cual se pretende evitar de manera expresa, que se puedan desconocer los principios y basamentos jurídicos de un orden normativo fundamental.

\section{Interpretación y uniformidad de la ley como fines nomofilácticos}

La interpretación es un proceso que consiste en determinar el significado o alcance de las normas jurídicas para dar una solución exacta al caso concreto. El basamento de las decisiones interpretativas es fundamental para lograr la adecuación en cada caso de la norma que debe servir para lograr la regulación de un supuesto verdadero de motivación de derecho, en torno a una determinada realidad; lo que beneficia a los justiciables en la medida que se ofrece seguridad jurídica.

La tarea interpretativa le permite al juzgador actuar en función de que se resguarde la norma de derecho, con lo que se establece el sentido unívoco de una acepción legal que les permita a los particulares lograr la protección de sus derechos. La interpretación de la norma jurídica con fines nomofilácticos se fundamenta en que en un Estado 
constitucional se busca que la hermenéutica de la ley se base en la lógica sistemática o valorativa, para descubrir y establecer el espíritu, propósito y razón de la norma.

La uniformidad de la ley se deriva de la igualdad procesal consagrada en las constituciones, la cual persigue proteger a cada una de las personas. En base a esto, la función nomofiláctica se expresa como la interpretación del derecho aplicada a todos por igual. La función nomofiláctica viene a ser la interpretación uniforme de la ley desde la casación, cuyo fin fundamental es unificar la jurisprudencia nacional, a partir de cada caso particular, verificando si la ley ha sido o no vulnerada por sentencia de un tribunal inferior o distinto, en busca de que no se infrinja el derecho de igualdad, por lo tanto, viene a ser la unificación de la jurisprudencia a partir de la interpretación y aplicación de las normas jurídicas de manera uniforme.

Con la casación, el Estado asegura la unificación, la igualdad del derecho y la uniformidad de la jurisprudencia. A través del estudio de las interpretaciones de una misma norma jurídica, la jurisprudencia disminuye la diversidad de criterios en torno a un mismo tema, lo que se traduce en la defensa o conservación de la ley.

Para que exista una efectiva tutela judicial, debe haber una aproximación de la justicia al justiciable, y eso es posible cuando hay simplificación, uniformidad y eficacia en los trámites procesales. En este sentido es necesario que a través de la casación emanen decisiones justas y ajustadas a derecho, de ahí que no se puede concebir la finalidad de la casación sin contar con la función nomofiláctica, que se traduce en la defensa de la ley.

En definitiva, las sentencias judiciales deben tener como finalidad la defensa del derecho objetivo, que no quiere decir la no interpretación de definiciones que nacen en los tribunales de distintos grados, sino un enfoque coherente, social, racional de los tribunales supremos en funciones de casación, aplicando con profundidad, el debido proceso, las normas y principios generales del derecho, y una concurrencia analítica de la norma jurídica sin desbordar el marco estructural que le corresponde para dar cumplimiento a sus funciones ante pueblos y sociedades que exigen y merecen una expedita y justa administración de justicia.

\section{La casación como unificación de la jurisprudencia}

La casación para algunos doctrinarios es un recurso, una acción o un medio de impugnación extraordinario ante una sentencia que debe presentarse ante el Tribunal Supremo, Corte Suprema o Corte Nacional, cuyo objetivo es aportarle firmeza o anular una decisión. Por su importancia y la función que cumple dentro del proceso es un mecanismo en el derecho procesal y su fundamento es el restablecimiento del imperio de la ley (Ibañez, 1957, p. 99). Esto significa que de ella se deriva la protección y el resguardo de la eficacia de la ley, que es, en esencia, la nomofilaxis.

La terminología de nomofiláctico, en el orden casacional tiene por basamento, fiscalizar la aplicación de la ley en las resoluciones judiciales. Por lo tanto, la casación, busca la correcta, efectiva y análoga aplicación de las leyes y de las disciplinas jurisprudenciales, y en tal sentido su finalidad va más allá de los intereses de las partes procesales.

Con la nomofilaxia, la casación viene a permitir la tutela de la ley, al tiempo que propende a la unificación de la jurisprudencia, todo ello porque se relacionan en una misma función, logrando que lo uno y lo otro se acoplen y ordenen para lograr una 
verdadera justicia. Así mismo, el fin de velar por el cumplimiento de la ley, tributa a la unidad de la jurisprudencia y al cumplimiento uniforme de una política casacional y judicial instituida por las máximas cortes judiciales.

La casación consta de dos características que la distinguen de otros recursos; en primer lugar, se fundamenta en el interés público para atender también intereses particulares, procurando con ello contribuir a la consecución de la seguridad jurídica, y en segundo lugar, es un recurso extraordinario, de última instancia que tiene por objeto el control de la legalidad. Sus finalidades clásicas son: la defensa del derecho objetivo y la unificación de la jurisprudencia, a través de lo cual se logra la correcta aplicación del derecho, se asegura la no vulneración de los principios de seguridad jurídica, igualdad, certeza, previsibilidad jurídica y judicial, y se propende a resguardar la presencia válida de la norma de derecho objetivo.

Para Torres la casación tiene dos aspectos: uno tiende a impedir que los órganos jurisdiccionales se valgan del poder de mandar, en concreto, que el Estado ha delegado en ellos, sustrayéndose a la norma fundamental cuya observancia constituye la condición sine qua non de aquel poder y otro aspecto en cuanto tiende a asegurar en el Estado la uniformidad de la jurisprudencia y, por consiguiente, la unidad y la igualdad del derecho objetivo (Torres, 2007, p.123-124).

El Tribunal Supremo o máximo tribunal, no se basa en destruir, sino en disciplinar y fijar la integración del derecho que se lleva a cabo de forma ininterrumpida por la jurisprudencia, por ello, las funciones nomofiláctica, la unificación y uniformidad de la ley, se acoplan en un interés social, es decir buscan los mecanismos especializados para resguardar y ejecutar de manera correcta el orden público.

La unidad de la jurisprudencia significa no una unidad monolítica sobre los diferentes y variados casos sometidos en los tribunales, ni la eliminación de la diversidad de opiniones que deben ser generadas sobre las grandes decisiones que siempre se generan alrededor de puntos específicos hasta su esclarecimiento, significa un estudio, reflexión constante, una revisión de los puntos, un examen de las posiciones mantenidas por los tribunales superiores, y por los tribunales de grado, una aceptación de las corrientes doctrinales que ejercen su influencia a través de la crítica y la perspectiva, que se oponen al ciego seguidismo, que contribuyen a evitar un conocimiento mediocre del derecho. (Arguello, 2005, p. 56).

Por lo tanto, es necesario y fundamental que los tribunales cuenten con jueces bien formados y capacitados, cuya labor sea la de analizar, buscar y crear en forma objetiva y crítica las mejores fórmulas de interpretación y aplicación de la Ley para impartir una verdadera y eficaz administración de justicia. De los jueces se esperan decisiones correctas, fundadas, objetivas e imparciales. Por lo tanto, es un deber, el velar por la vigencia y absoluto respeto al ordenamiento jurídico, lo cual es posible a través de un control de jerarquía que se debe tener sobre la labor que realizan los que imparten justicia en los tribunales inferiores.

En la actualidad se exige que los jueces en su actividad como directores del proceso, garanticen la imparcialidad y la independencia en el ejercicio de sus funciones, en virtud de que el proceso viene a constituir un instrumento esencial para la aplicación de la justicia. Corresponde a ellos adoptar las medidas necesarias para garantizar que no se produzcan vulneraciones o transgresiones a los derechos de las partes 
intervinientes. Por lo tanto, corresponde a la casación, realizar el efectivo control y unificación de la jurisprudencia.

\section{Función nomofiláctica como interpretación uniforme}

Uno de los aspectos importantes dentro del ámbito procesal es la función nomofiláctica en el sistema judicial como interpretación uniforme, pues se trata de un medio de resguardo del orden constitucional donde se persigue establecer la preeminencia de los derechos fundamentales frente a declaraciones de infracción o quebrantamiento del orden jurídico. Ella tiene un carácter purificador y protector que encierra la validez de la seguridad jurídica.

La función nomofiláctica constituye una garantía de que no se produzcan violaciones continuadas del ordenamiento jurídico; de allí que se pueda contribuir a fortalecer la esencia del sistema legal en todos sus extremos de manera tal que se pueda conservar la aplicación del espíritu, propósito y razón propia de la norma de orden público. Por lo tanto, la función nomofiláctica debe llevar a apartar falsas fundamentaciones de derecho y a reforzar la presencia de las normas adecuadas de manera que no se pueda generar una incertidumbre o ambigüedad en los criterios del sistema jurídico.

Al respecto, Sarmiento, se ha señalado que:

A través de la función nomofiláctica se tiene por fin que el juez de casación en nuestro caso las Salas de Casación Civil, Penal o Social anule las sentencias que conforme a su criterio contienen infracciones legales, no sólo por la injusticia que envuelven, sino porque reflejan la contumacia del juez de instancia frente a la ley que le crea un imperativo concreto e inexcusable. (Sarmiento, 2002, p.35)

La nomofilaxia se presenta en la casación, como medio rápido para la protección debida del ordenamiento jurídico en el criterio de la integralidad normativa, cuyo mecanismo convierte a los dictámenes judiciales en fuentes para la creación de criterios ilustrativos sobre la trascendencia del orden normativo en el ámbito de la integralidad del sistema jurídico positivo.

La función de unificación de la jurisprudencia está encargada a las cortes de casación o máximo tribunal, para proteger y amparar, no solamente la igualdad de todos los justiciables ante la ley, sino la unidad del derecho objetivo nacional, que quedaría vulnerado por otras interpretaciones. Se parte del señalamiento que, en materia de interpretación, se debe mantener como vinculantes las decisiones que emana del máximo tribunal, pues, por esta vía de interpretación, fija métodos para el afianzamiento y reconocimiento de las normas jurídicas que deben considerarse para preservar de manera efectiva la unificación de las normas dentro del sistema judicial.

De esta forma la función nomofiláctica como medio de protección integral del orden legal es necesaria y fundamental para evitar que se descomponga el espíritu de los principios normativos del derecho en dictámenes, en esencia controvertidos, que pudiesen llevar a la inseguridad jurídica.

En el ámbito del derecho comparado la función nomofiláctica en Colombia se fundamenta en la defensa de la ley llamada nomofilaxia, cuyo propósito principal de la casación es la purificación del derecho objetivo. Parra expresa que, "Este fue inicialmente el fin buscado por la casación y por ende la creación de un tribunal que se encargara de la ley contra aquellas sentencias violatorias de estas". (Parra, 2000, p.27). 
En Colombia la función nomofiláctica debe entenderse a partir de que las causales del recurso de casación de acuerdo con la normativa que rige a ese país son, que la decisión sea violatoria o vulnere la ley de carácter sustancial, cuyas causales pueden ser por infracción directa, aplicación indebida o interpretación errónea. De esto se asume que la procedencia del recurso se activa cuando se desconoce y vulnera la esencia del derecho objetivo.

En España, las motivaciones del recurso de casación son el abuso, exceso o defecto en el ejercicio de la jurisdicción, incompetencia o inadecuación de procedimiento, quebrantamiento de las formas esenciales del juicio, por infracción de las normas reguladoras de la sentencia o de las que rigen los actos y garantías procesales, siempre que, en este último caso, se haya producido indefensión para la parte.

Por lo tanto, la existencia del recurso de casación debe supeditarse a la fundamentación del acto decisorio en una vulneración del orden público fundamental, en los supuestos de orden normativo que atenten contra la rectitud del orden legal. De esta manera se promueve el resguardo del sistema legal en su contenido normativo.

En el ámbito del derecho laboral, el elemento significativo de la casación es velar por la aplicación del derecho objetivo y crear jurisprudencia, uniformando la misma a través de un órgano supremo que repara la vulneración del derecho objetivo de las partes. Ello le permite afirmar a Ugalde sobre su esencia, "su valor protector de los derechos de los litigantes". (Ugalde, 2009, p.39).

Con respecto a Perú, la casación se fundamenta en la infracción normativa que incida directamente sobre la decisión contenida en la resolución impugnada o en el apartamiento de los precedentes vinculantes dictados por el Tribunal Constitucional o la Corte Suprema de Justicia de la República. Tiene como precedente el hecho de que se haya desconocido o alterado la esencia del derecho objetivo, de manera tal que se propenda a configurar un medio de corrección y rectificación del orden jurídico para fortalecer los medios de garantía y protección de las personas e instituciones del Estado.

De igual manera se entiende la esencia de la función nomofiláctica en ese país, donde el recurso de casación es una petición nomofiláctica, según lo expresa Paredes, "mediante la cual un órgano especial que es el tribunal de casación aprovechándose de la iniciativa privada, vigila y fiscaliza la observancia de las leyes por parte de los tribunales, a efecto de que prevalezca la ley": (Paredes, 2007, p.86).

Todo lo anterior se traduce en establecer que la interpretación de la Ley es una y verdadera y lo que se quiere es que se establezca el verdadero significado de la ley, permitiendo con ello, instaurar una línea jurisprudencial como antecedente para las decisiones y así contribuir a la seguridad jurídica. En ese sentido, para Jiménez la casación, "se configura como el instituto procesal adecuado para proporcionar una unitaria interpretación del derecho". (Jiménez, 1999, p.310).

De esto se entiende que la casación persigue la apropiada aplicación en los fallos judiciales y de esta manera se garantiza la estabilidad de las instituciones y la vigencia auténtica de la ley, sobre derechos investidos y amparados eficazmente ante desconocimientos o vulneraciones que se hacen a través de la acción restablecedora de la justicia. 
En Venezuela, se admite que la Sala Constitucional pueda ejercer la función nomofiláctica en el supuesto de que se propenda a determinar la consistencia de una norma jurídica. La incidencia del recurso de casación es pronunciarse sobre los actos que pueden quebrantar el orden fundamental de la ley, lo cual compete al juez establecer si existe o no una vulneración o desaplicación de un orden jurídico debido, de manera que se puede ratificar la existencia del régimen jurídico regular para fortalecer los derechos de los justiciables. De esta forma se entiende que la función nomofiláctica se materializa en torno a las variables del recurso de casación en los supuestos de la defensa del orden jurídico fundamental por esa vía.

Bajo este contexto, se reconoce que la función nomofiláctica es un medio de afianzamiento de la seguridad jurídica, en virtud de que permite que los fallos judiciales puedan atenerse de manera consecuente con los lineamientos debidos del orden jurídico, esto evita su relajamiento o quebrantamiento reiterado. Por lo tanto, se busca establecer el sistema de justicia y las instituciones, de manera que se pueda resguardar la legitimidad del estamento normativo e institucional en procura que se protejan los derechos de los particulares.

De allí que, la función estudiada propende a establecer medios de resguardo de la norma fundamental que conduzcan a afirmar la validez del orden sustantivo y adjetivo formal, con miras de que no se generen los vicios de inconstitucionalidad o de ilegalidad dentro del orden normativo.

El resultado de la relación entre la función nomofiláctica y la casación es que, esta última, tiene una finalidad tutora del ius constitutionis del ordenamiento jurídico, en dos vías como lo señala San Martín: “a) la función monofiláctica, que importa la protección o salvaguarda de las normas del ordenamiento jurídico; y, b) la función uniformadora de la jurisprudencia en la interpretación y aplicación de las normas jurídicas". (San Martín, 2003, p.992).

La activación de esta forma funcional puede servir para que se corrobore la constitucionalidad de los actos, en el entendido de que se pueda establecer un medio de protección que pueda evitar la proliferación de actos antijurídicos o propensos de desviación de derecho. Por ello, el objeto y finalidad de la nomofilaxia, es el resguardo del derecho objetivo, o sea, tanto la norma sustantiva como la adjetiva. Ello tiene unas características propias como: la bilateralidad, la generalidad, la imperatividad y la coercibilidad.

La existencia de la norma de derecho objetivo, es decir, la de preceptos reconocidos e impuestos como normas de orden público de parte del legislador, no pueden ser desconocidas por el sistema judicial por entenderse la superioridad de la decisión de carácter legislativo. En este contexto se establece que deben resguardarse los bienes jurídicamente tutelados en el orden normativo.

En definitiva, se debe propender a la configuración de un mecanismo de revisión y depuración de dictámenes judiciales, de manera que se pueda descartar la desviación de derecho y se pueda fundamentar un resguardo del orden jurídico de correcta incidencia en el caso particular de estudio. El recurso de casación es esencialmente considerado de derecho público, pues con él se puede satisfacer el interés del Estado, a través de la exacta observancia de la ley en la administración de justicia. Pero a su vez, busca proteger los derechos de las partes intervinientes en un litigio, a fin de 
dar la oportunidad de objetar ante el Tribunal Superior, la decisión que consideran les causa un gravamen.

Lleva así la casación, una dualidad donde los justiciables encuentran el mecanismo perfecto para la defensa de sus derechos ius litigatioris, y donde el Estado mediante los Tribunales de casación, logran la unificación del orden jurídico ius constitutionis, lo que se traduce en la relación existente entre el recurso de casación y la función nomofiláctica. (Alcalá y Castillo, 1985, p.386).

La firmeza de la función nomofiláctica, le permite no sólo revocar aquellas decisiones que vulneren la ley ordinaria, sino también como lo expresa Gimeno, "a interpretarla de una manera uniforme mediante la emisión de su doctrina legal. Esa función, a través de la casación, ha asumido la totalidad de los tribunales supremos". (Gimeno, 2005, p.65).

En cuanto a la sustancia material, se puede señalar que, la casación cumple una función nomofiláctica, que corresponde a la protección del ordenamiento jurídico en un sentido formal. (Neyra, 2007. p.38), en ese criterio se comprende que la consecuencia de esta función repercute de manera directa en la salvaguarda del orden jurídico, al punto que se descarte y desvirtúe cualquier norma infundada que pudiese traducirse en el cercenamiento de los derechos individuales y colectivos que pudiese tenerse en cuenta.

Es indudable que la función nomofiláctica se utiliza para explicar la existencia de un orden normativo vulnerado, así como el restablecimiento de la situación jurídica infringida o lesionada. De esta forma se comprende que se puede salvaguardar el orden jurídico y en la misma medida posible sentar criterios coherentes que propendan a fijar mayor seguridad para los justiciables.

En definitiva, la hermenéutica de la norma jurídica es para esclarecer la relevancia del orden jurídico de manera que no se convierta en contumaz o se contribuya reiterativamente a sentar dictámenes que puedan significar la desarticulación del deber ser de la norma. Esto facilita la creación de mecanismos de defensa más efectivos para lograr el resguardo de los derechos objetivos fundamentales.

\section{Conclusiones}

La interpretación de las normas jurídicas en cualquiera de sus variantes debe realizarse desde una perspectiva axiológica, sistemática y valorativa de forma tal que se evite contrariar el verdadero sentido de la ley.

La nomofilaxia tiene como finalidad, la unificación de la ley como medio de instaurar el respeto a la legislación vigente con efectos expansivos hacia todos los órganos jurisdiccionales que imparten justicia de forma tal que pueda contribuirse a la seguridad jurídica.

El alcance o propósito de la nomofilaxis en casación es declarar la nulidad o revocar las decisiones contrarias al orden jurídico, de forma tal que pueda conseguirse con su aplicación una mayor consistencia del marco legal que ha sido aprobado por la sociedad y el Estado.

En el ámbito del recurso de casación puede desarrollarse un estricto control de la legalidad y la unificación de la jurisprudencia porque a través de las sentencias se 
conforman criterios vinculantes de obligatorio cumplimiento, con el fin de proteger constantemente la vigencia del derecho objetivo.

En la etapa contemporánea, aun con las críticas de que la casación es objeto, bajo pretexto de alcanzar la justicia en el caso concreto, no pueden los jueces hacer uso de ella en contra de la ley pues la función nomofiláctica de la casación perdura y debe garantizar la preservación del régimen normativo vigente.

\section{Referencias}

Alcalá y Castillo, N. (1985). Derecho Procesal Laboral. Buenos Aires.

Arguello, P. (2005). La Nomofilaxis en el Derecho. España. Arte.

Cafferata, J. (2003). Manual de Derecho Procesal Penal. Buenos Aires: Ciencia, Derecho y Sociedad.

Chiovenda, G. (1940). Instituciones de Derecho Procesal Civil, Las relaciones procesales. Tomo. III. Madrid: Editorial Revista de Derecho Privado.

De la Rúa, F. (2000). La Casación Laboral. Buenos Aires. De Palma.

Fenech, M. (1992). Derecho Procesal Penal. Madrid. Labor

Gimeno, V. (2005). El recurso español de casación civil: perspectiva de reforma. Madrid. Civitas.

Gómez, D. (2011). La jurisprudencia Laboral y sus Incidencias en Venezuela, Trabajo de Grado de Maestría no publicado. Universidad de Carabobo.

Guasp, J. (1950). Actas del I Congreso Nacional de Derecho Procesal. Madrid.

Hitters, L (1995). Breve Reseña Histórica de la Casación Civil Francesa. Madrid. ED.

Ibañez, F. (1957). Tratado de los Recursos en el Proceso Civil. Buenos Aires.

Jiménez, F (1999). El Recurso de Casación para la Unión de la Doctrina Laboral. Barcelona. Ariel.

Neyra, J. (2007). El Recurso de Casación Laboral. Lima. JUS Jurisprudencia

Paredes, J. (2007). El Recurso de Casación: Su Visión Peruana. Lima. Apurímac.

Parra, R. (2000). Recurso de Casación Laboral y Casación Administrativa. Bogotá. ecoe.

Pastor, D. R. (2001). La nueva imagen de la casación Penal. Buenos Aires : AD-HOC.

Pérez, D. (2011). Interpretación de la Jurisprudencia en el Derecho Comparado. Trabajo de grado de Maestría no publicado. Universidad Bicentenaria de Aragua.

Porras, L. (2005). La Unificación del Derecho. Chile. Letras. 
San Martin, C. (2003). Derecho Procesal Laboral. Lima. Grijley.

Sarmiento, J. (2002). Análisis de Estudios de Casación. Caracas. Serie de Estudios Jurídicos.

Torres, Y. (2007). La Unificación de la Sentencia. Barcelona. Ariel.

Ugalde, J. (2009). Recurso de Casación Laboral. Madrid. La ley.

Vescovi, E. (1998). Los Recursos Judiciales y demás Medios Impugnativos en Iberoamérica Buenos Aires. Depalma. 